\title{
The Contribution of Distributional Justice to Siting Transmission Lines
}

\section{Garry Keegan and Ann M. Torres}

\begin{abstract}
The purpose of this article is to present an introduction to the literature concerning policy and theoretical considerations in the challenging environment of siting electricity transmission lines in local communities. The research literature in this area is underdeveloped with few practical manifestations of the concept. While there is evidence of high levels of public resistance to the siting of overhead lines, there is a gap regarding initiatives to help them become more socially acceptable.
\end{abstract}

\section{Keywords}

Distribution, justice, transmission lines, siting, community

\section{The Contribution of Distributional Justice to Siting Transmission Lines Introduction}

In Ireland, over the past few decades, there have been numerous disputes related to public policy infrastructure projects. In reviewing these disputes, there is consistency with respect to objectors' arguments and in the approach of the state body charged with project delivery. These disputes lead to acrimonious public debate, project delays and considerable increased costs. Examples of such projects in the energy, transport and waste management sectors include EirGrid high voltage overhead transmission line (HVOTL) projects, Corrib Gas 'Shell to Sea' campaign, and projects promoted by Dublin City Council such as Dublin Port Tunnel and the Ringsend Waste Management Facility. These major infrastructure public policy projects, which result in prolonged and expensive multi-party disputes, are drawn into the political arena, where projects become the subject of election manifestos with the various political parties emphasising different public policy issues. Hence, when there are changes in government and the 'inherited' infrastructure projects go against the incoming government's espoused policy, it inevitably creates difficulties. An example of such a scenario is the Ringsend 'Incinerator' project, proposed to be located in Sandymount / Ringsend, a popular residential area of Dublin City. This project has been in gestation for many years, has been hotly debated in the public policy and political arenas, and has to date absorbed close to $€ 100 \mathrm{~m}$ on a project that may not go ahead (RTE, 2013). 
With some projects, such as the development of electricity transmission or wind farms, government departments are in sync. For example, at the national level, the Department of Energy, Communications and Natural Resources and the Department of the Environment are deeply involved, jointly responsible, and typically like-minded in developing transmission and wind farm projects. However, local authority municipalities, which such projects straddle, may employ a wide range of policies. Although local politicians appreciate infrastructure projects are matters of national policy, and may privately acknowledge the need for such infrastructure, they are often compelled to defend project objectors' positions. Developing a 'coalition of the willing' is challenging under these circumstances.

Each time a new 'national need' infrastructure project is initiated, it encompasses a multitude of public policy and community stakeholders, and the potential for conflict is high. The question is how to learn from past mistakes? Is conflict inevitable? What measures minimise conflict while also respecting stakeholders' varying perspectives? The literature offers insufficient empirical research in assessing the effectiveness of environmental related disputes, which is often referred to as environmental mediation, environmental conflict resolution or public policy dispute resolution (Amy, 1983; Dukes, 2001, Emerson et al., 2009). Interest has grown in consensus building, facilitation, mediation, and other forms of resolving conflict through assisted negotiation and voluntary settlement (Innes and Booher, 1999; Daniels and Walker, 2001; Wondolleck, 2010). The concept of early intervention, preceded by an 'assessment' stage, is seen as important in achieving ultimate mediation success in environmental disputes (Susskind et al, 1999; Bean et al. 2007; Moore, 1996; McCarthy and Shorett, 1984).

Three trends are noted by Susskind (2009) as emerging in alternative dispute resolution (ADR) processes applied to environmental conflict resolution. The first of these is bringing likely adversaries together earlier, before conflict escalation. The second trend is focusing on improvement of long-term capacity within organisations to deal with conflict, and the third trend involves institutionalising resolution of public disputes. Susskind (2009) anticipates increasing examples where there will be an obligation to specify mediation as part of zoning, permitting, licensing, facility siting, and other environmental related processes. He makes the case it is much easier implementing dispute resolution endeavours where mandatory ground rules exist.

The two types of disputes public policy mediation handle are opposition to siting of specific public services or new developments; and shaping and making public policy. Public opposition to the siting of facilities which are promoted to benefit a region (e.g., airports, military bases, industrial plants, prisons, power plants - hydro, solar, nuclear, oil and gas refineries, and waste management sites), that are locally unwelcome is a well-documented social issue, attracting considerable attention in the literature (Gallagher at al., 2008; Schively, 2007; Powe and Willis, 1998; Wolsink, 1994). While proponents of private or public facilities search for strategies designed to achieve public acceptance, opposition groups regularly demonstrate a capacity to halt or delay new projects using a variety of 
legal and political tactics. Through these actions, they consistently and continually thwart efforts to successfully deliver rational planning initiatives to meet environmental needs. They expose the inherent weaknesses of facility siting processes in effectively balancing regional and/or national needs and locally perceived negative impacts.

\section{Electricity Transmission Siting Difficulties}

Although, there is considerable research on the complexities associated with wind farm development, there is a research gap regarding community benefit agreements. Little research has been conducted on benefit sharing in the context of community acceptance and siting HVOTLs. While there is evidence of high levels of public resistance to the siting of overhead lines, there is a lacuna regarding initiatives to facilitate their social acceptance.

Cotton and Devine-Wright (2011) note the dearth of research on the social-cultural issues surrounding the process of electrical transmission line siting. They observe how siting HVOTLs and substations are publicly controversial due to their environmental, social, and economic impacts. It is unclear how socio-political and community acceptance is developed to siting HVOTLs in Ireland and which actions can be taken to develop positive acceptance towards siting them.

Host community benefit agreements (HCBAs) are now an acceptable feature of developing wind-farms in Ireland. Although it is Government policy to have community gain associated with the development of transmission line projects, there is a knowledge vacuum of how to approach this difficult subject in an effective manner. The Irish Government Policy Statement of the Strategic Importance of Transmission and other Energy Infrastructure (July 2012) acknowledges the need for social acceptance and the appropriateness of energy project developers examining appropriate means of building 'community gain' considerations into project planning and budgeting. A better understanding of the role of HCBAs should assist policy makers with the siting of HVOTL projects.

A tension exists between a growing need for transmission capacity and the nature of differing planning and implementation processes at local and regional level (Fischlein et al., 2013). Grid development is facing considerable challenges in the immediate future, which will contribute to the endangerment of security of supply and limiting the trade of electric energy. Despite the mounting need for grid infrastructure investments to meet demand, because of dated and life-expired grids, it is increasingly difficult to secure new line permitting and construction (Buijs et al., 2011). The lack of local community acceptance leads to long delays, protracted legal challenges and major cost burdens to utilities, generators and ultimately the public (Cain and Nelson, 2013). The development of new electricity transmission lines is one of the most extreme examples of facility siting difficulty (Vajjhala, 2007). One study highlights the public's negative perception of new transmission lines, as $82 \%$ of respondents considered them to adversely affect the natural landscape (Soini, 2011). The Association for Conflict Resolution (ACR) Environment and Public Policy Section (2009) outlines the issues associated with transmission lines siting and how organised stakeholders can make the 
siting of a locally unwanted transmission line project an extremely difficult process.

Although most wind farm developers have established protocols for HCBAs, these protocols do not exist for siting overhead power lines. Such projects throughout Ireland, UK and Continental Europe are encountering a sense of urgency to deliver, but they are experiencing significant cost overruns and time delays. Public resistance among host communities is leading to numerous problems for national governments in terms of energy supply security and meeting renewable energy target obligations. The energy sector is under pressure to meet renewable energy targets and to progress interconnection among European countries.

Cowell et al. (2011) scrutinise the conventional argument that HCBAs generate greater social acceptance of wind farms, making the case that community benefits should not only be seen as compensating for impacts but also as promoting environmental justice. If the Irish Government's plans for renewable energy expansion materialise, one result may be a proliferation of community benefit funds percolating throughout relatively sparsely populated rural areas. This potential outcome emphasises the importance of policy makers and project proponents giving careful thought to the role, purpose, negotiation, design and management of community benefit agreements. In the context of researching how to improve acceptance and legitimacy for Germany's 380kv grid extension, Sander (2012: 70) recommends further research on "compensation of individuals or potential benefit sharing" and "how compensation could help to increase acceptance of grid extension projects."

Diamond (2011: 227) identifies numerous cases where there is a demonstrated need for energy reliability and local opposition delayed transmission line projects, noting:

... local opposition to a major electricity infrastructure facility is at the heart of its failure to be built, and in a highly charged, politicised atmosphere, demonstration of public need for the facility seems inadequate to persuade local landowners to its favour. Indeed, a project's success is usually dependant on site- specific circumstances, including local economic conditions, the community's need for tax revenues that would flow from the facility's development, population density, and the composition of local political bodies responsible for the siting process.

Mediation is found to be highly successful in reconciling land-use disputes (Diamond, 2011). A research study of land-use conflict resolution processes that involved mediation found $86 \%$ of participants viewed the process favourably, and $85 \%$ believed the mediator was critical to achieving a successful outcome (Susskind et al., 1999). 


\section{Defining Communities}

Boynes-Watson (2006) explores what 'community' actually means explaining it may have positive or negative connotations in terms of association, inclusion or exclusion. How and by whom community benefit agreements are negotiated may be subject to intense negotiations by a coalition of representatives from a diverse community (Aitken, 2011). Who is 'in' and who is 'out' of the coalition is important with respect to accountability and legitimacy. Hence, local authority officials and developers may negotiate agreements with preferred groups that may not reflect the full range of community concerns. In this context, Aitken (2011) explores who are the local community and what constitutes a legitimate project. She believes "communities of place do not constitute communities of interest" (Aitken, 2011: 6073).

Similarly, McCold and Wachtel (1998) argue community is not defined by geography, where a person or groups of persons are located, but how people perceive themselves to be connected to others. Hence, how people network, interact, participate in groups, and feel a sense of belonging is what defines a community; proximity does not infer connectedness (Aitken, 2011; McCold and Wachtel; 1998). Community psychology also plays a role in informing community development practices by reframing social capital theory (Perkins, Hughey and Speer, 2002). Social capital can be defined at different levels, as either interpersonal, community, institutional, or societal within which networking and relationships prevail. A geographical community definition conveys a territorial context such a neighbourhood, village, town or city (McMillan and Chavis, 1986). Different forms of community are not mutually exclusive (Gusfield, 1975); modern society develops community around interests and skills, rather than around locality (Mendieta Y Nunez, 1964).

There are variations and contingencies in a 'community system' and mechanisms can be designed to reinforce behaviours leading to an iterative sense of community (Glenwick and Jason, 1980). Hence, project promoters should consider how the local community is defined. For example, communities may comprise of those who are impacted (e.g., visual, noise, traffic), share an interest (e.g., sport, cultural, religious), or on a territorial basis (e.g., historical, administrative, geographical). The political and electoral system can play an important role in how a community is defined, as how the community self-defines as a 'town-land' or 'parish'. Defining community in the context of a 'corridor' or 'linear alignment' project for siting an electricity transmission line plays an important role in negotiating and administering a community benefit agreement.

\section{Community Acceptance}

It is unclear how socio-political and community acceptance has developed to siting HVOTLs in Ireland and which actions can be taken to develop positive acceptance towards siting HVOTLs. The term social acceptance is frequently used in public policy and because precise definitions are rarely given. Wustenhagen, Wolsink and Burer (2007) identify three interdependent dimensions of social acceptance (see Figure 1). 


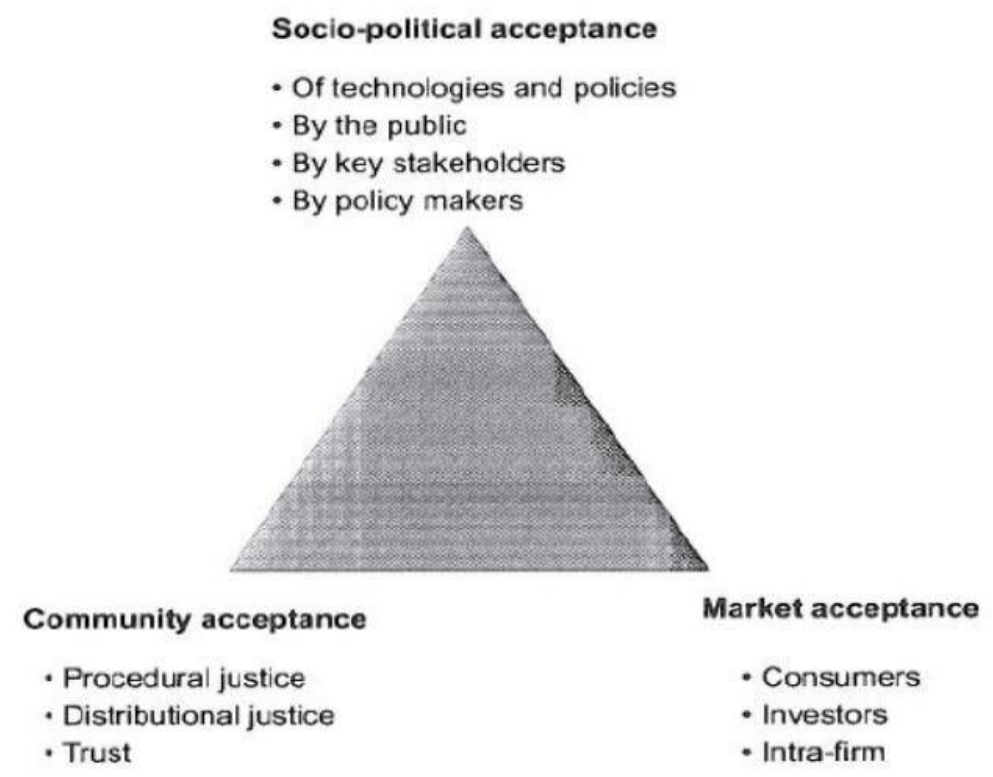

Fig. 1. The triangle of social acceptance of renewable energy innovation.

Source: Wustenhagen, Wolsink and Burer (2007: 2684) (Adaption of Figure 1, Section 2.1, The Triangle of Social Acceptance of Renewable Energy Innovation)

Community acceptance may be defined as local stakeholders' (i.e., residents and local authorities) specific approval of siting decisions and renewable energy projects (Wustenhagen et al., 2007). The factors influencing community acceptance are the relative importance of distributional justice (i.e., mechanism or framework for sharing costs and benefits), procedural justice (i.e., fairness of decision-making process for all relevant stakeholders to participate), and the level of trust for the investors' and actors' intentions and the information they provide (Wustenhagen et al., 2007). Community acceptance is an emerging area of study and further research is warranted, as opposition from local groups is a main obstacle in the timely and effective completion of HVOTL projects. The European Network of Transmission System Operators for Electricity (ENTSO-E) (2010) recognise electricity infrastructure projects are neither considered as being necessary, nor does the general public understand their benefits. As a result, numerous individuals and groups object to a project at regional planning procedure and project approval stages.

Perceiving community benefits as a way for fostering social acceptability suggests an insufficient comprehension of the complex nature of acceptability, how it relates to the institutions governing decision-making, and resource use (Cowell 2007). It ignores the multiplicity of ways stakeholders involved in development processes interpret and rationalise these practices (Cass et al., 2010) by conflating acceptance with acceptability (Szarka et al., 2007).

The time dimension and longitudinal aspect of siting a project is an important feature of community acceptance. The classic U-curve can typify the pattern of community acceptance, experiencing high acceptance at the beginning, following a downward trajectory during the planning 
and construction phases and returning to high acceptance post-completion (Wolsink, 2007). It can be argued in modern society and a democracy, public decisions should be acceptable to those people who will be affected by them (Laws, 1996). However, people may interpret the concepts of 'social' and 'acceptance' differently. Social may refer to society as a whole and its different groupings (e.g., consumers, producers) and acceptance can range from passive consent (e.g., the silent majority) to active approval in the form of vigorous involvement. Cain and Nelson's (2013) framework integrates existing theories in exploring siting outcomes. In the siting process, the community shapes an individual's "sense of place", the project's perceived impact, and the level of trust among stakeholders (Cain and Nelson, 2013: 207). When the level of opposition is high, those located in close proximity to each other may create 'community based organisations'. They create a sense of belonging and purpose, and then have the organisation, structure, ability and momentum to campaign and lobby relevant stakeholders. This group interaction enables individuals to oppose projects, otherwise their impact on large-scale projects, such as HVOTLs, would be limited.

Ellis et al. (2007) conclude, from their exploration of discourses of support and objection, "the understanding of the motivation to either object or support a wind farm proposal defies simple explanation, yet much previous work in this area has inspired to locating precise and quantifiable answers to what are, ultimately, matters that reflect deep values and conviction" (Ellis et al., 2007: $540)$.

\section{Distributional Justice}

"Distributive justice focuses on the equitable distribution of outcomes for public goods (e.g., infrastructure) and public burdens (e.g., hazardous waste)" (Gross, 2007: 2729, citing Kuehn, 2000: 10684). Political theorists and justice commentators view social justice as a subcategory of justice (Gross, 2007). In his discussion of the relationship between environmental sustainability and social justice, Dobson (1998) notes while the distribution of benefits and burdens is frequently associated with social justice, it also characterises the idea of justice. Distributional justice is a central tenet of environmental justice theory, as is procedural justice, which focuses on the fairness of decision-making processes. "Social scientists have recognised that justice is a key issue in our lives", and "a number of theories deal with people's concerns about fairness" (van den Bos et al. (1997: 95).

For instance, equity theory states people judge an outcome as fair when the ration of their own inputs and outputs equals the ration of inputs and outputs of comparison to others. Another important notion of justice is formulated in relative deprivation theory, which argues people judge an outcome as unfair when the outcomes they receive fall short of their expectations. Although equity theory and relative deprivation theory differ in certain aspects, they are theories of distributive justice, because they focus on outcome fairness (van den Bos et al. (1997: 95).

Unfair outcomes or the perceptions thereof may lead to acrimony among communities. Relationships among groups and individuals may be damaged for the short or long term, resulting in 
a fractured community, which may be as a result of elevated expectations from a process that were not delivered. Some members of the community may have benefited, or have been perceived to have benefited, more than others (Gross, 2007). Communities are "influenced by different aspects of justice, namely by outcome fairness, outcome favourability and process fairness" (Gross, 2007: 2727).

The acceptability of the provision of public goods versus monetary compensation in response to public harms is explored by Mansfield et al. (2002), whose research suggests a public goods offering is more desirable and acceptable than monetary compensation. Mors et al. (2012: 130), in the context of researching siting Carbon Capture and Storage (CCS) facilities, conclude that "while host community compensation is no panacea, it has the potential to help prevent or solve (CCS) facility siting controversies."

\section{Conclusion}

There are three major HVOTL projects proposed in Ireland (e.g., Grid Link, Grid West and the North South Interconnection Development), each of which traverses several counties comprising many affected communities. Together these projects represent over $€ 1$ billion in investment. The North South Interconnector traverses an approximate $140 \mathrm{~km}$ linear corridor of $400 \mathrm{kv}$ overhead electricity line, with and associated infrastructure. This proposed interconnection development, at an estimated cost of $€ 300$ million investment, extends between the existing electricity transmission network in Northern Ireland to the existing transmission network in the Republic of Ireland. Research is urgently need to the examine the design and management of community benefit agreements among host communities of HVOTL projects, and the extent to which their introduction, negotiation and application can contribute to community acceptance of such projects. A better understanding of the role of benefit agreements in this little researched area would assist policy makers with the difficulty in siting controversial HVOTL projects. 


\section{References}

Aitken, M. (2010) 'Wind power and community benefits: challenges and opportunities', Energy Policy 38, 6066-6075, Elsevier.

Amy, D (1983) Ecology Law Quarterly. The Politics of Environmental Mediation. Ecology Law Quarterly, Vol. 11.1.

Bean, M., Fisher, L., and Eng, M. (2007) "Assessment in Environmental and Public Policy Conflict Resolution: Emerging Theory, Patterns of Practice, and a Conceptual Framework." Conflict Resolution Quarterly, 24(4), 447-468.

Boynes-Watson, C. (2006) 'Community is not a place but a relationship: lessons for organisational development', Public Organisation Review: A B=Global Journal 5: 359-374 (2005), Springer Science \& Business Media Inc.

Buijs, P., D. Bekaert, S. Cole, D. Van Hertem, R. Belmans (2011) 'Transmission investment problems in Europe: Going beyond standard solutions', Energy Policy, 39, 1794-1801, Elsevier.

Cain, N.L., H.T. Nelson (2013) 'What drives opposition to high-voltage transmission lines?' Land Use Policy, 33, 204-213, Elsevier.

Cass, N., G. Walker, P. Devine-Wright (2010) 'Good neighbours, public relations and bribes: the politics and perceptions of community benefit provision in renewable energy development', Journal of Environmental Policy and Planning, 12 (3), 225-275.

Cotton, M., P. Devine-Wright (2011) 'Discourses of energy infrastructure development: a Q- method study of electricity transmission line siting in the U.K.', Environment and Planning, A Vol. 43, 942-960.

Cowell, R. (2007) 'Wind farm development in Wales: assessing the community benefits. A research project for the Welsh Assembly Government Cardiff.

Cowell, R., G. Bristow, M. Munday (2011) 'Acceptance, acceptability and environmental justice: the role of community benefits in wind energy development', Journal of Environmental Planning and Management, Vol. 54, No. 4, 539-557, Routledge.

Daniels, S. and Walker, G. (2001) Collaborative Learning: Improving Public Deliberation in Ecosystem Based Management.

Diamond, M. (2011) 'Energizing Negotiations: Mediating disputes over the siting of interstate electric transmission lines', Ohio State Journal of Dispute Resolution, Vol 26:1, 217-269

Dobson, A. (1998) Justice and the Environment: conceptions of environmental sustainability and theories of distributive justice', Oxford University Press, Oxford.

Dukes, E.F. (2001) Integration in Environmental Conflict." Conflict Resolution Quarterly,

Vol.19, 1, 103-115.

Ellis, G., J. Barry, C. Robinson (2007) 'Many ways to say no, different ways to say yes: applying qmethodology to understanding public acceptance of wind farm proposals', Journal of Environmental Planning and Management, Vol. 50, No. 4, 517-551, Routledge. 
Emerson, K., Orr, P., Keyes, D., and Mcknight, K. (2009) Environmental Conflict Resolution: Evaluating Performance Outcomes and Contributing Factors. Conflict Resolution Quarterly, Vol.27, No. 1.

ENTSO-E (2010) Position paper on permitting procedures for electricity transmission infrastructure. (ENTSO-E - European Network of Transmission System Operators).

Fischlein, M., E.J. Wilson, T.R. Peterson, J.C. Stephens (2013) 'States of transmission: moving towards large-scale wind power', Energy Policy, http://dx.doi.org/101016/J.enpol.2012.11.028 Gallagher, L., Ferreira, S and Convery, F. (2008) Host Community Attitudes towards solid waste landfill infrastructure: comprehension before compensation', Journal of Environmental Planning and Management, 51: 2, 233 - 257

Glenwick, D., L. Jason (1980) behavioural community psychology: progress and prospects, Praeger, New York.

Government policy statement on strategic Importance of transmission and other energy infrastructure (2012) Department of Communications, Energy and Natural Resources, Policy Document.

Gross, C. (2007) 'Community perspectives of wind energy in Australia: the application of a justice and community fairness framework to assess social acceptance', Energy Policy, 35, 2727-2736.

Gusfield, J.R. (1975) Community: A critical response, Harper and Row, New York (ISBN $0061361763)$

Innes, J.E., D.E. Booher (1999), 'A framework for evaluating collaborative planning', Journal of the American Planning Association, Vol. 65, No. 4, 412-423, American Planning Association.

Kuehn, R. (2000) 'A taxonomy of environmental justice', Environmental Law Reporter 30, 10681 10703.

Laws, D. (1996) 'The Practice and Fairness', Environment Impact Assessment Review, 16: 65- 70, Elsevier.

Mansfield, C., G.L. Van Houtven, J. Huber (2002) 'Compensating for public harms: why public goods are preferred to money. Land Economics 78, 368-389.

McCarthy, J., A. Shorett (1984) Negotiating settlements: A guide to environmental mediation. New York: American Arbitration Association.

McCold, P., Wachtel, B. (1998) Restorative policing experiment: The Bethlehem Pennsylvania Police Family Group Conferencing Project, U.S. Dept. of Justice, Washington

D.C. (NCJRS 177564).

McMillan, W., D.M. Chavis (1986) Sense of Community: A definition and theory.

Mendieta Y. N. (1964) Emile Durkheim: The State and Democracy. Journal for the Scientific Study of religion, Vol. 3, No. 2, 255-260.

Moore, C.W. (1996) The Mediation Process: Practical Strategies for Resolving Conflict (2 ${ }^{\text {nd }}$ ed.) San Francisco: Jossey-Bass. 
Perkins, D., J. Hughey, P.W. Speer (2002) Community psychology perspectives on social capital theory and community development practice, Journal of Community Development Society, Vol 33, No. 1. Powe, N. and Willis, K. (1998) Industrial location and residential disamenity: a case study of the chemical industry in Castleford, England. Journal of Environmental Management, 53, 17-29

RTE (2013) Dublin City manager Owen Keegan has said the Poolbeg project has proved extremely challenging and it has gone on for far too long, as reported at www.rte.ie/news January 22nd 2013. Sander, A. (2011) From Decide, Announce, Defend to Announce, Discuss, Decide? Thesis, Lund, Sweden.

Schively, C. (2007) Understanding the NIMBY and LULU Phenomena: Reassessing Our Knowledge Base and Informing Future Research. Journal of Planning Literature, 21: 255. Soini, K, E. Pouta, M. Salmiovirta, M. Vusitalo, T. Kivinen (2011), Local resident's perceptions of energy landscape: the case of transmission lines, Land Use Policy 28, 294-305, Elsevier.

Susskind, L. (2009) Twenty-Five Years Ago and Twenty-Five Years from Now: The Future of Public Dispute Resolution, Negotiation Journal.

Susskind, L., S. McKearnan, J. Thomas-Larmer (1999) The Consensus Building Handbook: A Comprehensive Guide to Reaching Agreement, London, sage.

Szarka, J. (2007) Wind power in Europe. Politics Business and Society, Basingstoke: Palgrave MacMillan.

Ter Mors, E., B.W. Terwel, D.L., D.D.L. Daamen (2012) 'The potential of host community compensation in facility siting', International Journal of Greenhouse Gas Control, 11S, S130- 138, Elsevier.

Vajjhala, S.P., P.S. Fischbeck (2007) 'Quantifying siting difficulty: A case study of US transmission line siting', Energy Policy, 35, 650-671, Elsevier.

Van Den Bos, K., R. Vermunt, H.A.M. Wilke (1997) 'Procedural and Distributive Justice: what is fair depends more on what comes first than what come next',

Journal of Personality and Social Psychology, Vo. 72, No. 1, 95-104, American Psychological Association.

Wolsink, M. (2007) 'Planning of renewable schemes. Deliberative and fair decision-making on landscape issues instead of reproachful accusations of non-cooperation', Energy Policy 35 (5).

Wolsink, M. (1994) 'Entanglement of interests and motives: assumptions behind the NIMBY- theory of facility siting', Urban Studies, 31, pp. 851-866.

Wondolleck, J. (2010) A Crack in the Foundation? Revisiting ECR's Voluntary Tenet. Conflict Resolution Quarterly, vol. 27, 3, 321-345.

Wustenhagen, R., M. Wolsink, M.J. Burer (2007) 'Social acceptance of renewable energy innovation: An introduction to the concept', Energy Policy, 35, 2683-2691, Elsevier. www.acrepp.org 
Garry Keegan is one of Ireland's leading conflict intervention experts in the area of energy and transport infrastructure development. Apart from his environmental mediation and multi-party public policy work, Garry also lectures extensively and conducts training courses.

Garry holds an MBS in Marketing from University College Dublin and an MA in Mediation from the National University of Ireland Maynooth. He is currently researching a $\mathrm{PhD}$ at the National University of Ireland Galway on Community Benefit Agreements and siting Electricity Transmission Lines.

Dr. Ann M. Torres is a Lecturer in Marketing at the J.E. Cairnes School of Business and Economics and the Vice Dean of Internationalisation for the College of Business, Public Policy and Law at the National University of Ireland Galway. She spent 2013 as a Visiting Fellow in the Program on Negotiations at Harvard Law School, Harvard University. Her research interests are situated in the convergence of strategy, entrepreneurship and innovative marketing practices. Her interest in negotiating theory and practice adds an additional dimension to these topics. With respect to her publications, she is recognised as an accomplished case writer, earning more than a half-dozen awards for her work. Ann obtained an MBA from the University of California, Berkeley and her PhD from Trinity College Dublin. 